\title{
Effect of ferroresonance on wind turbine: comparison of ATP/EMTP and matlab/simulink
}

\author{
Ajibola O. Akinrinde, Andrew Swanson, Remy Tiako \\ School of Electrical, Electronics and Computer Engineering, University of KwaZulu-Natal, South Africa
}

\begin{abstract}
Article Info
ABSTRACT

Article history:

Received Nov 19, 2018

Revised Jan 1, 2019

Accepted Jan 25, 2019

Different developers have produced several software packages as solutions to model electrical power systems for the purpose of carrying out diverse analyses to solve immediate and unforeseen problems in power systems. In this study, ATP/EMTP and Matlab/Simulink packages were compared in regards to their capability to give accurate results, time of simulation and ease of simulation when modelling DFIG wind turbine. Furthermore, ferroresonance caused by one stuck pole during switching operations were

\section{Keywords:}

DFIG wind turbine

Ferroresonance

ATP/EMTP

Simulink/Matlab analyzed on both software. Characterization of resulting ferroresonance was done using Fast Fourier Transform (FFT) analysis, phase plane diagram and Poincaré mapping. Chaotic mode ferroresonance was found in during opening event while quasi-periodic existed for closing events. ATP could only perform FFT analysis but other analyses were performed on Matlab/Simulink. There were differences in the results obtained from the two packages; overvoltage of 4.22 P.U. and 3.77 P.U. was experienced during opening and closing operation on ATP/EMTP model while 6.36 P.U. and 4.63 P.U. respectively was obtained on Matlab. However, ATP was faster in regards to time of simulation with CPU time of 110.58 secs and simulink simulation time was 130.81 secs. Finally, it was easier to carry out the simulation on Simulink.
\end{abstract}

Copyright (C) 2019 Institute of Advanced Engineering and Science. All rights reserved.

\section{Corresponding Author:}

Ajibola O. Akinrinde,

School of Electrical, Electronics and Computer Engineering,

University of KwaZulu-Natal,

238 Mazisi Kunene Road, Glenwood, Durban, 4041,KZN, South Africa

Email: tunjiakinrinde@yahoo.com

\section{INTRODUCTION}

Doubly-fed inductor generator (DFIG) wind turbine is the most used wind turbine generator in the world today, with its usage rising above $85 \%$ of functioning wind turbines [1]. The main advantage of DFIG wind turbine is its ability to operate with varying wind speed without stressing its mechanical and electrical components. Other advantages of DFIG include; it is less expensive, it is capable of controlling reactive power, it has high power efficiency and it reduces power variation. Modelling wind energy systems using power systems software for the purpose of carrying out several analyses is necessary, considering the high initial cost of implementation. Advantages of analyzing power systems on software include and are not limited to the following; problems could be predetermined and solutions can be proposed, service time of the equipment can be prolonged, response of the system under different scenarios can be evaluated, downtime could be reduced and running cost eventually reduced.

Temporary overvoltage is one of the issues that occur on any power system. It involves oscillation which exists for long duration of time, which could be damped or weakly damped. Events leading to temporary overvoltage include; resonance, ferroresonance, load rejection, fault clearing and harmonics. Ferroresonance is considered in this paper due to the severity of damage on transformers which is one of the most expensive equipment in power systems. Ferroresonance could occur on wind power systems due to the interaction of nonlinear inductor and capacitor when a disturbance occurs in the system. Ferroresonance could lead to high 
permanent overcurrent and overvoltage, displacement of neutral point voltage, overheating in transformer and excessive continuous loud noise from the transformer [2,3]. Power systems simulation software can be used to simulate, analyze potential threats and mitigating solutions can be obtained.

There are numerous power systems software available today, some of these software could have good performance for a particular analysis and may not be effective for other analyses when compared to real power systems. ATP/EMTP and MATLAB are packages common among researchers to carry out analyses on power systems. Alves and Orizondo [4] compared the use of ATP/EMTP and Matlab/Simulink program to simulate unified power flow controller (UPFC). The UPFC was implemented by using two voltage source converters coupled through a DC link capacitor. It was found that ATP calculation speed is faster than that of MATLAB due to the nature of the solver algorithm. ATP/EMTP and Matlab/Simulink were compared for time domain transient studies by Danyek et al. [5]. The two packages were used in lightning surge simulation and it was concluded that MATLAB offers more possibilities and options for signal processing and control. Simulation of arc faults using ATP and Simulink for comparison was done by Khan and Bengiamin [6]. Cassie arc model was simulated in two circuit schematics and the comparison was done in both time and frequency domain. Time step of $1 \mu \mathrm{s}$ and sample time $0.2 \mathrm{~s}$ were used for the two packages. The results were similar for both time and frequency domain and it was added that the little difference is as a result of the modelling of electrical passive components such as capacitors and inductors rather than solver algorithms. Three tools; EMTP, MATLAB and XTRANS were compared by Schavemaker, et al. for electrical transient computations. Simulation of electric arc using Schwarz arc model with time step of $6 \mu$ s was performed on all the tools. XTRANS was found to be best of the three in terms of user-friendliness, MATLAB was found to be the most effective package in terms of programming freedom and flexibility while EMTP gave the best solution and could be used for larger simulations [7]. Barsali and Ceraolo [8] did simulation of electromagnetic transient in power systems comparing ATP and Simulink using different time steps. It was concluded that simulation took less time on ATP while Simulink result is more accurate and simulating large circuit is easier on it. In this paper, the two packages are compared for temporary overvoltage, with emphasis on ferroresonance on DFIG wind turbine, for accuracy, time of simulation and ease of simulation. Post-analyses were also done for the output signals by characterizing the ferroresonance.

\section{ATP/EMTP}

ATP evolved from electromagnetic transient program (EMTP) as experts around the world started contributing to it since 1975. ATP was developed for the public in 1984 at Bonneville Power Administration (BPA) of Portland, Oregon. ATP has also developed over the years and ATPDraw was birthed at Norwegian University of Science and Technology, Norway. ATPDraw is a graphical mouse driven preprocessor, which works by dragging and dropping predefined components to design a power network model. ATPDraw converts the generated model to input file for ATP simulation [9].

ATP simulation is performed as a function of time, using trapezoidal rule of integration to solve the differential equations of the power network components. In addition, model verification can be done in frequency domain, where users can specify geometry and the specification of the device. Various predefined components in ATP include but are not limited to; passive electrical elements such as resistors, inductors and capacitors, transformers, rotating machines, switches, electrical sources, surge arresters transmission lines and cables. Furthermore, ATP has the capacity to model control systems through the aid of two features; Transient Analysis of Control Systems (TACS) and MODELS (a programming language). ATP/EMTP is used for various EMTP applications which are not limited to the following; insulation coordination, switching overvoltage analysis lightning overvoltage analysis, protective relay modelling, power quality studies and shaft torsional oscillation studies. There are post-processors that are interfaced with the ATP which are used to display results [9].

\section{SIMULINK/MATLAB}

Matrix Laboratory which is abbreviated as "Matlab" is technical computing software which started approximately 70 years ago based on earlier library such as LINPACK. It started as a program to handle any matrix problem but eventually grow up to be used in various mathematical applications. MATLAB as a computing environment has other file extensions such as Simulink, Simscape and MUPAD, which makes it more robust and enables it to perform more technical computations. Simulink is a graphical environment for modelling, simulating and analyzing dynamical systems. Simulink contains preset blocks called libraries which contain linear, non-linear, continuous and discrete functions that could be used to represent any system to be analyzed. Simulink has gained popularity among researchers working in power systems these days, this is due 
to its elaborate libraries, ability to customize the libraries and interfacing capability of diverse program modules.

\section{RESEARCH METHODOLOGY}

Modelling of DFIG wind turbine and simulation of ferroresonance using ATP and Simulink are the methodologies used in this paper. Figure 1 shows the major components for generating power from wind. The wind speed must be greater than the cut-in speed (about $12 \mathrm{~m} / \mathrm{s}$ ), so as to create enough torque to run the generator. The generator is connected via the gear box which adapts the speed of the turbine to the generator speed. The rotor of the generator converted the kinetic energy of the turbine to mechanical energy and the electrical energy is obtained from both the stator side of the generator and the rotor side via the back-to-back converter. The output power is $0.69 \mathrm{kV}$ which was stepped up to $33 \mathrm{kV}$ by the wind turbine transformer and supplied to the grid.

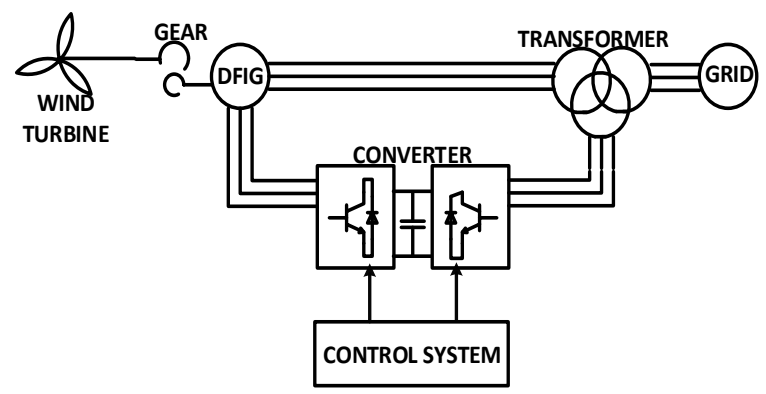

Figure 1. DFIG wind turbine configuration.

\subsection{Wind Simulation}

Wind speed at any location varies with time and season. One of the ways to represent wind speed is by using probability distribution function (PDF) [10]. The most commonly used PDF is Weibull distribution, however, the wind speed can be forecast using Weibull distribution as shown in Equation (1);

$$
F(V)=\frac{K}{W}\left(\frac{V}{W}\right)^{k-1} e^{\left[-\left(\frac{V}{W}\right)^{K}\right]}
$$

Where $F(V)$ is frequency of occurrence for wind speed, $V$ is frequency distribution, $W$ is empirical Weibull scale factor, $K$ is empirical Weibull shape factor.

\subsection{DFIG Wind Turbine and Generator}

The power output of wind turbine is represented in Equation (2). The DFIG wind turbine generator was modelled according to [11].

$$
\mathrm{P}_{\mathrm{m}}=\frac{1}{2} \rho A v^{3} \mathrm{C}_{\mathrm{p}}(\lambda, \beta)
$$

Where $A$ is the swept area, $\rho$ is the density of the air, $v$ is the speed of the wind and $C_{p}$ is the power coefficient of the turbine, which depends on tip speed ratio, $\lambda$ and pitch angle, $\beta$. Tip speed ratio can be represented by Equation (3):

$$
\lambda=\frac{\omega_{\mathrm{r}} \mathrm{R}}{\mathrm{V}}
$$

Where $\omega_{r}$ is the angular velocity of the rotor. $\omega_{r}=\frac{2 \pi n}{60}$, and $\mathrm{n}$ is revolution $/ \mathrm{min}$ The equation to obtain optimal $\mathrm{C}_{\mathrm{p}}$ is given in Equation (4):

$$
C_{p}(\lambda, \beta)=C_{1}\left(\frac{C_{2}}{\lambda_{1}}-C_{3} \beta-C_{4}\right) e^{\frac{-C_{5}}{\lambda_{1}}}+C_{6} \lambda
$$

Where $\mathrm{C}_{1}, \mathrm{C}_{2}, \mathrm{C}_{3}, \mathrm{C}_{4}, \mathrm{C}_{5}$ and $\mathrm{C}_{6}$ are $0.71,1.49,0.56,13.1,0.182$ and 0.004 respectively. Where, 


$$
\begin{aligned}
& \frac{1}{\lambda_{1}}=\frac{1}{\lambda+0.08 \beta}-\frac{0.035}{\beta^{3}+1} \\
& \mathrm{P}_{\mathrm{m}}=\mathrm{T}_{\mathrm{m}} \omega_{r} \\
& \mathrm{P}_{\mathrm{s}}=\mathrm{T}_{\mathrm{em}} \omega_{s} \\
& \mathrm{P}_{\mathrm{r}}=-\mathrm{S} \mathrm{T}_{\mathrm{em}} \omega_{s}
\end{aligned}
$$

For a lossless generation operating in a steady state;

$$
\begin{aligned}
& \mathrm{T}_{\mathrm{m}}=\mathrm{T}_{\mathrm{em}} \\
& \mathrm{P}_{\mathrm{r}}=\mathrm{P}_{\mathrm{m}}-\mathrm{P}_{\mathrm{s}}
\end{aligned}
$$

Substituting Equation 7, 8 and 9 into 10, Equation 11 is obtained.

$$
S=\frac{\omega_{S}-\omega_{r}}{\omega_{S}}
$$

Where, $P_{r}$ and $P_{s}$ are power output for rotor and stator of the DFIG respectively, $T_{m}$ and $T_{e m}$ are the aerodynamic torque of the turbine and electromagnetic torque of the generator, $\omega_{s}$ is the angular velocity of the stator and $\mathrm{S}$ is the slip of the generator.

DFIG is an induction generator having a configuration where its stator is connected directly to the load and its rotor, is connected to the load through power converter. The operation of DFIG can easily be explained in two axes, $\mathrm{d}$-q coordinate frame. The conversion from $\mathrm{ABC}$ to dq is done using park transformation in Equation (12).

$$
\begin{aligned}
& {\left[\begin{array}{l}
d \\
q \\
0
\end{array}\right]=\frac{2}{3}\left[\begin{array}{ccc}
\cos \theta & \cos \left(\theta-\frac{2 \pi}{3}\right) & \cos \left(\theta+\frac{2 \pi}{3}\right) \\
-\sin \theta & -\sin \left(\theta-\frac{2 \pi}{3}\right) & -\sin \left(\theta+\frac{2 \pi}{3}\right) \\
\frac{1}{2} & \frac{1}{2} & \frac{1}{2}
\end{array}\right]\left[\begin{array}{l}
A \\
B \\
C
\end{array}\right]} \\
& \mathrm{V}_{\mathrm{sd}}=\mathrm{R}_{\mathrm{s}} \mathrm{I}_{\mathrm{sd}}+\frac{d \varphi_{s d}}{d t}-\omega_{s} \varphi_{s q} \\
& \mathrm{~V}_{\mathrm{sq}}=\mathrm{R}_{\mathrm{s}} \mathrm{I}_{\mathrm{sq}}+\frac{d \varphi_{s q}}{d t}+\omega_{s} \varphi_{s d} \\
& \mathrm{~V}_{\mathrm{rd}}=\mathrm{R}_{\mathrm{r}} \mathrm{I}_{\mathrm{rd}}+\frac{d \varphi_{r d}}{d t}-\omega_{r} \varphi_{r q} \\
& \mathrm{~V}_{\mathrm{rq}}=\mathrm{R}_{\mathrm{r}} \mathrm{I}_{r q}+\frac{d \varphi_{r q}}{d t}+\omega_{r} \varphi_{r d} \\
& \varphi_{\mathrm{sd}}=\mathrm{L}_{\mathrm{s}} \mathrm{I}_{\mathrm{sd}}+\mathrm{L}_{\mathrm{m}} \mathrm{I}_{\mathrm{rd}} \\
& \varphi_{\mathrm{sq}}=\mathrm{L}_{\mathrm{s}} \mathrm{I}_{\mathrm{sq}}+\mathrm{L}_{\mathrm{m}} \mathrm{I}_{\mathrm{rq}} \\
& \varphi_{r \mathrm{~d}}=\mathrm{L}_{r} \mathrm{I}_{r \mathrm{~d}}+\mathrm{L}_{\mathrm{m}} \mathrm{I}_{s \mathrm{~d}} \\
& \varphi_{r q}=\mathrm{L}_{r} \mathrm{I}_{r q}+\mathrm{L}_{\mathrm{m}} \mathrm{I}_{s \mathrm{q}} \\
& \mathrm{L}_{\mathrm{s}}=\mathrm{L}_{\mathrm{is}}+\mathrm{L}_{\mathrm{m}} \\
& \mathrm{L}_{r}=\mathrm{L}_{\mathrm{ir}}+\mathrm{L}_{\mathrm{m}}
\end{aligned}
$$

Where $\mathrm{V}_{\mathrm{sd}}, \mathrm{V}_{\mathrm{sq}}$, are the stator voltages in $\mathrm{d}$ and $\mathrm{q}$ axis respectively and $\mathrm{V}_{\mathrm{rd}}, \mathrm{V}_{\mathrm{rd}}$ are the rotor voltages in $\mathrm{d}$ and $\mathrm{q}$ axis respectively, $R_{\mathrm{s}}, R_{r}$ are the stator and rotor resistance respectively, $\mathrm{L}_{\mathrm{s}}, \mathrm{L}_{r}$ are the stator and rotor inductance respectively, $\mathrm{L}_{\mathrm{is}}, \mathrm{L}_{\mathrm{ir}}$ are the stator and rotor self-inductance respectively, $\mathrm{L}_{\mathrm{m}}$ is the mutual inductance, $\mathrm{I}_{\mathrm{sd}}$, $\mathrm{I}_{\mathrm{sq}}$ are the stator currents in $\mathrm{d}$ and $\mathrm{q}$ axis respectively $\mathrm{I}_{\mathrm{rd}}, \mathrm{I}_{\mathrm{rq}}$ are the rotor currents in $\mathrm{d}$ and $\mathrm{q}$ axis respectively, $\varphi_{s d}, \varphi_{s q}$ are the stator fluxes in $\mathrm{d}$ and $\mathrm{q}$ axis respectively and $\varphi_{r d}, \varphi_{r q}$ are the rotor fluxes in $\mathrm{d}$ and $\mathrm{q}$ axis respectively. 
The torque, active power and reactive power generated by the generator can be obtained using Equation (23), (24) and (25):

$$
\mathrm{T}_{\mathrm{e}}=1.5 \mathrm{~N}_{\mathrm{p}} \frac{\mathrm{L}_{\mathrm{m}}}{\mathrm{L}_{\mathrm{s}}}\left(\mathrm{I}_{\mathrm{sq}} \varphi_{\mathrm{sd}}-\mathrm{I}_{\mathrm{sd}} \varphi_{\mathrm{sq}}\right)
$$

Where, $\mathrm{N}_{\mathrm{p}}$ is the number of poles of the generator.

$$
\begin{aligned}
& P_{s}=\frac{3}{2}\left(V_{s q} I_{s q}+V_{s d} I_{s d}\right) \\
& Q_{s}=\frac{3}{2}\left(V_{s q} I_{s d}-V_{s d} I_{s q}\right)
\end{aligned}
$$

Table 1 shows the parameters of the wind turbine DFIG used in both ATP and MATLAB model.

Table 1. Parameters of DFIG wind turbine

\begin{tabular}{ll}
\hline Parameters & Values $(\mathrm{Ohm})$ \\
\hline Mutual inductance & 0.8436 \\
Stator resistance & 0.0023 \\
stator inductance & 0.029 \\
Rotor resistance & 0.0073 \\
Rotor inductance & 0.033 \\
\hline
\end{tabular}

The grid parameters used in the simulation is shown in Table 2, where the X/R ratio is approximately 6. However, the parameter of the filter was calculated based on the cut-off frequency of the filter which is $10 \%$ of the carrier frequency. Hence, the parameter of the filter was calculated based on Equation (26);

$$
\mathrm{f}_{\mathrm{c}}=\frac{\mathrm{R}}{2 \pi \mathrm{L}}
$$

Table 2. Grid parameters

\begin{tabular}{ll}
\hline Parameters & Values \\
\hline Grid voltage & $33 \mathrm{kV}$ \\
Fault level & $10 \mathrm{MVA}$ \\
Grid resistance & $0.2 \Omega$ \\
Grid inductance & $4.26 \Omega$ \\
\hline
\end{tabular}

\subsection{Converters and Their Control}

The back-to-back converter is rectifier and inverter connected through a DC link. This scheme allows control of reactive power at the grid. The rotor side converter (RSC) controls the active and reactive power delivered by stator by ensuring that it is needed according to the mechanical torque. However, the grid side converter (GSC) controls the power delivered to the grid by ensuring the voltage at the DC link is constant. The control scheme of both RSC and GSC is shown in Figure 2.

$$
\begin{aligned}
& \mathrm{k}_{1}=\frac{\mathrm{L}_{\mathrm{s}} \mathrm{T}_{\mathrm{e}}}{\mathrm{N}_{\mathrm{p}} \varphi_{\mathrm{sd}} \mathrm{L}_{\mathrm{m}}} \\
& \mathrm{k}_{2}=\frac{1}{2} \mathrm{I}_{\mathrm{sd}} \mathrm{V}_{\mathrm{sq}} \\
& \mathrm{k}_{3}=\mathrm{S} \omega_{\mathrm{s}}\left(\sigma \mathrm{I}_{\mathrm{rd}} \mathrm{L}_{\mathrm{r}}+\varphi_{\mathrm{sd}} \frac{\mathrm{L}_{\mathrm{m}}}{\mathrm{L}_{\mathrm{s}}}\right) \\
& \mathrm{k}_{4}=\mathrm{S} \omega_{\mathrm{s}} \sigma \mathrm{L}_{\mathrm{r}} \mathrm{I}_{\mathrm{rq}} \\
& \sigma=1-\frac{\mathrm{L}_{\mathrm{m}}^{2}}{\mathrm{~L}_{\mathrm{r}} \mathrm{L}_{\mathrm{s}}}
\end{aligned}
$$

Where $\sigma$ is the dispersion coefficient of the generator. 


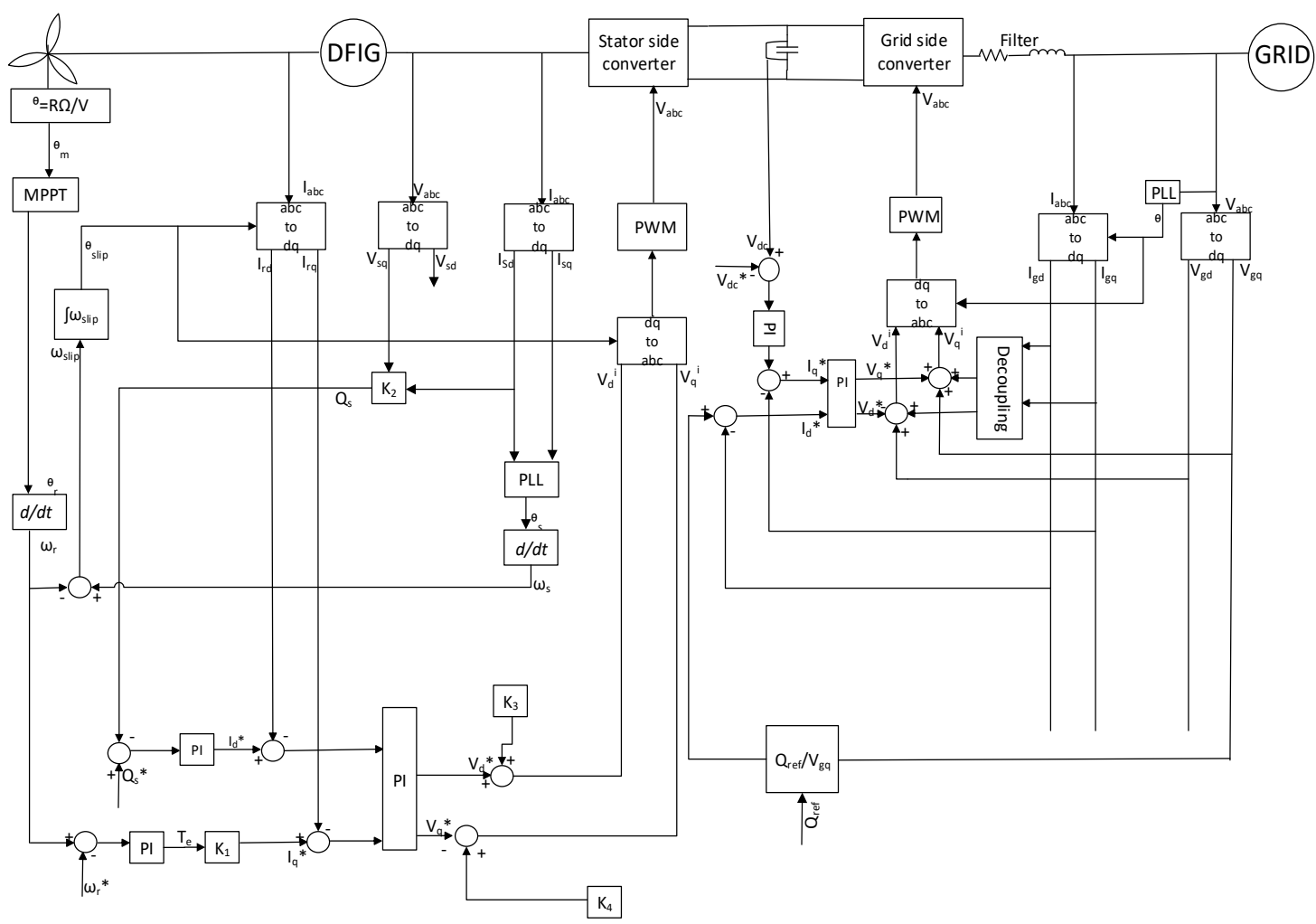

Figure 2. The control scheme of both RSC and GSC

\subsection{Transformer}

The wind turbine transformer is rated $0.69 / 33 \mathrm{kV}, 2.5$ MVA with vector configuration of DY7. According to [12], simulation of electrical transients which range in frequencies from dc to some $\mathrm{MHz}$ are divided into the four categories as shown in Table 3. The analysis in this study could be categorized under low frequency transient, thus transformer modelling was done according to the specification of Table 3 . Nonlinearity characteristic of the transformer is important while modelling for temporary overvoltage, the relationship between flux linkage and magnetizing current which can be calculated using Equation (32):

$$
I=a \lambda+b \lambda^{n}
$$

Where $I$ is the magnetizing current, $a$ and $b$ are the constant coefficient for linear and saturated region respectively, $\lambda$ is the flux linkage and $n$ is number of polynomial degree order of the saturation.

Table 3. Cigre standard for modelling transformer according to frequency range [12]

\begin{tabular}{|c|c|c|c|c|}
\hline Parameters & $\begin{array}{l}\text { Low frequency } \\
\text { Transients }\end{array}$ & Slow front Transients & Fast front transients & Very fast transients \\
\hline Short-circuit impedance & Very important & Very important & Important & Negligible \\
\hline saturation & Very important & Very important ${ }^{(1)}$ & Negligible & Negligible \\
\hline Iron losses & Important ${ }^{(2)}$ & Important & Negligible & Negligible \\
\hline Eddy current & Very important & Important & Negligible & Negligible \\
\hline Capacitive Coupling & Negligible & Important & Very important & Very important \\
\hline
\end{tabular}

(1) Only for transformer energization phenomena, otherwise important

(2) Only for resonance phenomena

\section{MODELLING DFIG WIND TURBINE CONFIGURATION ON ATP/EMTP}

Overview of DFIG wind turbine configuration on ATP is shown in Figure 3, which presents: simulation of the wind turbine, DFIG generator, back-to-back controller and control, and wind turbine transformer. 


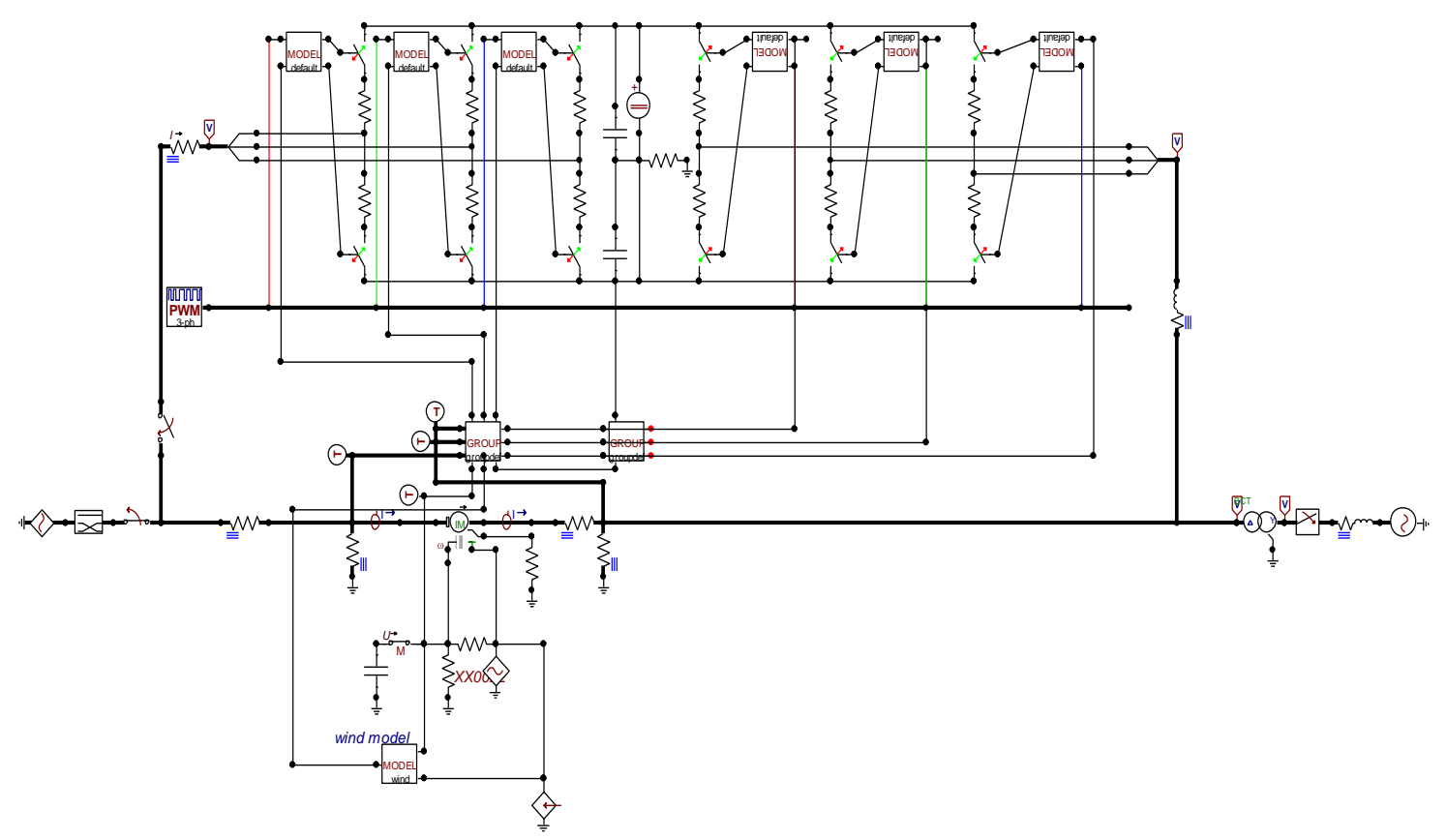

Figure 3. Overview of ATP model of DFIG wind configuration

\subsection{ATP Model of Wind Turbine and Generator}

DFIG is modelled using UM4 tool in ATP. According to ATP rule book [13], when modelling a single mass model, the mechanical elements are represented by equivalent electrical variables such that; Moment of inertia constant was represented by capacitance, damping coefficient was represented by conductance, while aerodynamic and electromechanical torque were represented as current source using (Type 60) and angular velocity was represented by voltage. This is shown in Figure 4 . Where, $R_{m}$ is small torque sensing resistor, $R_{c}$ is large resistor, $R_{x}$ is transmission cable, $D_{m}$ is damping coefficient, $J_{m}$ is the capacitive element and $T_{m}$ is a current source.

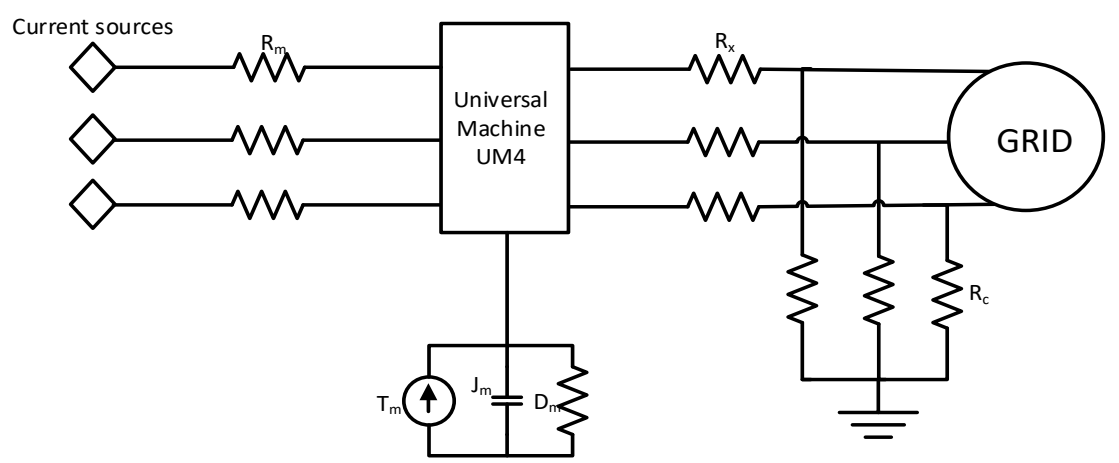

Figure 4. Electrical representation of mechanical elements of wind turbine and generator

\subsection{ATP Model of Back-to-Back Converter and Control}

Back to back converter which is made up of six pulse rectifier and inverter connected through DC capacitor is modelled by the use of TACS-controlled TYPE 13 switch. The operation of the switch is such that if one of the switches on a phase leg is opened, the other must be closed at all times. The logic through which the switches operate depends on output signal after the comparison of the output voltages of the generator and the modulating signal of pulse width modulation (PWM). PWM controls the output voltage for the converters by propagating a sawtooth signal which switches off to disallow passage of high frequency voltage output. PWM was done using MODEL, where the carrier frequency is $2 \mathrm{kHz}$. 


\subsection{ATP Model of Transformer}

ATP has three model types for transformer; saturable transformer component (STC) model, BCTRAN model and Hybrid model. The BCTRAN model is used to present the transformer. The model can be computed by considering steady state single phase multi-winding transformer in a matrix form as shown in Equation (33).

$$
[V]=[I][Z]
$$

The impedance $\mathrm{Z}$ in Equation 33, is the both the self-impedance of a phase and the mutual impedance of phases. However, for a transient study, Equation (33) would change to (34):

$$
[V]=[I][R]+\left[\frac{d I}{d t}\right][L]
$$

Where, $\mathrm{R}$ and $\mathrm{L}$ are the real and imaginary components of the impedance.

BCTRAN model can compute the core saturation of a transformer but cannot represent it. Hence, an external nonlinear inductance can be connected at the transformer terminal as shown in Figure 5.

In order to use this model, open and short circuit test data of the transformer is needed. The parameters of the wind turbine transformer used for this model is shown in Table 4 as found in [14].

The RMS voltage versus current data was converted to resultant $\lambda$ - I data by the BCTRAN supporting routine and curve fitting was done to improve the saturation curve as shown in Figure 6. The core saturation characteristic is implemented using pseudo-nonlinear hysterestic inductor TYPE 96 of ATP and it was placed at the low voltage terminal of the transformer.

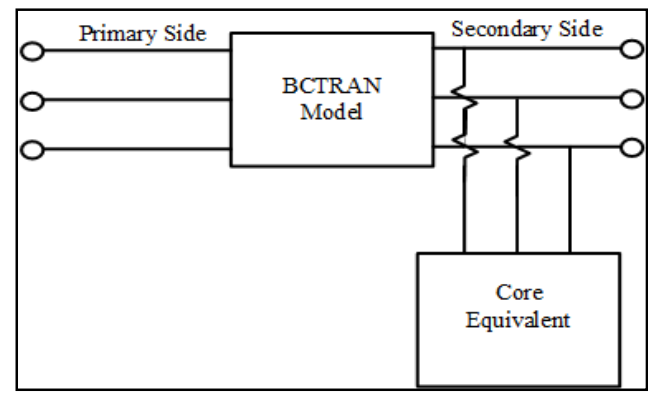

Figure 5. Schematic diagram of BCTRAN Model of two windings transformer with external non-linear representing the core [9]

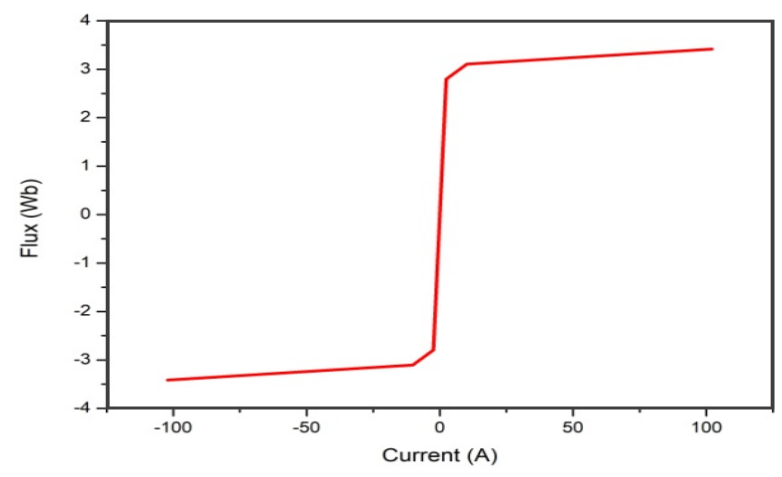

Figure 6. The nonlinearity characteristic curve of the wind turbine transformer.

Table 4. The test report of wind turbine transformer DY7

\begin{tabular}{cccc}
\hline Test & Voltage (\%) & Current (\%) & Power loss (kw) \\
\hline Open circuit test @ LV winding & 90 & 0.43 & 3.7 \\
& 100 & 0.9 & 5.5 \\
& 110 & 1.352 & 8.1 \\
& Impedance (\%) & Power (MVA) & Power loss (kw) \\
Short circuit test & 8.3 & 2.5 & 21 \\
\hline
\end{tabular}

Indonesian J Elec Eng \& Comp Sci, Vol. 14, No. 3, June 2019 : 1581 - 1594 


\section{RESULTS ON ATP}

\subsection{Simulation of Ferroresonance on ATP/EMTP}

Simulation time step of $5 \mu$ s and sample time $3 \mathrm{~s}$ were chosen for the simulation. Figure 7 shows the output voltage during normal operation of DFIG wind farm. Similar to [2], two switching events leading to ferroresonance were considered; Nuisance operation of the circuit breaker during opening and closing.

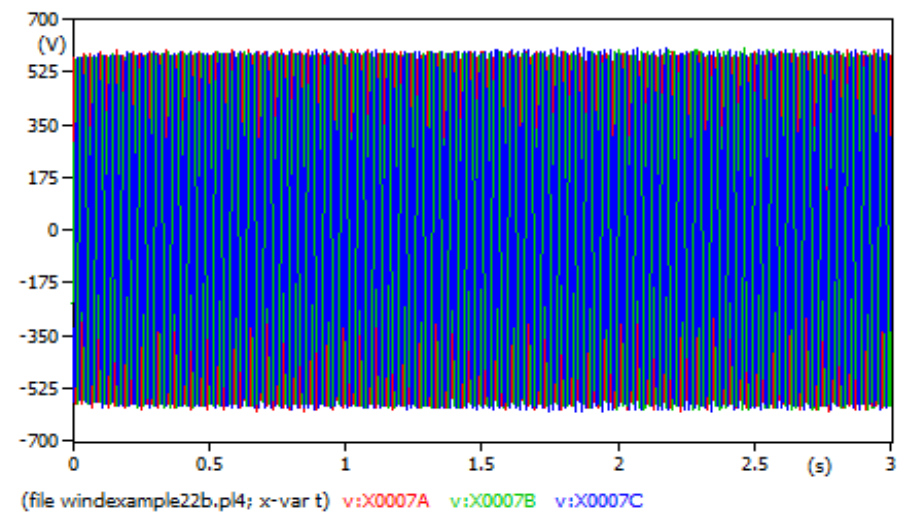

Figure 7. Output voltage of DFIG during normal operation on ATP

\subsection{Nuisance Operation of the Breaker During Opening and Closing on ATP}

The circuit breaker connecting the secondary side of the transformer was considered in this simulation. Either during the opening or closing operation of the breaker, all the three poles are expected to operate, but in a situation where one or two pole(s) get stuck during the process, this could lead to ferroresonance. Figure 8a shows resulting ferroresonance due to one stuck pole respectively during opening, and Figure $8 \mathrm{~b}$ shows ferroresonance during closing operation. Overvoltage of 4.22 P.U. and 3.77 P.U. was experienced during opening and closing event respectively. In both cases, the overvoltage was higher than the power frequency withstand voltage of the equipment according to [15] and could be dangerous for the equipment due to the undamped nature of the overvoltage.
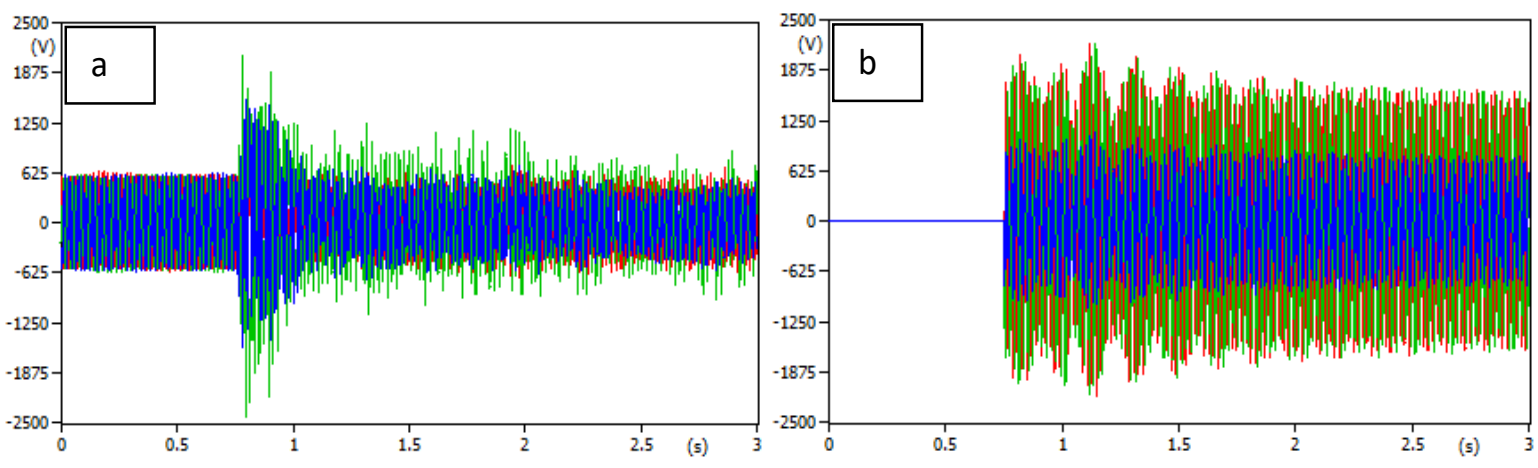

(file vindexample22b(real).pl4; $x$-var $t$ ) v:X0007A v:X0007B v:X0007C

(file vf5.pl4; $x$-var $t$ ) v:X0003A v:X0003B v:X0003C

Figure 8. (a). Output voltage due to a stuck pole during opening of circuit breaker on ATP and (b). Output voltage due to a stuck pole during closing of circuit breaker on ATP

\subsection{Characterization of Ferrosonance on ATP/EMTP}

Fast Fourier Transform (FFT) analysis was performed to characterize the spectrum of the harmonics. Characterization is needed in order to determine the type of ferroresonance existing in the system. FFT analysis exists as post-processor tool on ATP, thus FFT was done for the waveform between $0.8 \mathrm{~s}$ and $1.5 \mathrm{~s}$ and results are shown in Figure $9 \mathrm{a}$ and $9 \mathrm{~b}$ for the opening and closing ferroresonant event. In both cases, $1^{\text {st }}, 18^{\text {th }}$ and $20^{\text {th }}$ harmonic frequencies are very prominent in the spectrum. Chaotic or quasi-periodic mode ferroresonance may 
exist in the system due to non-periodic frequency that is continuous. Hence, further analysis is needed to better characterize the ferroresonance.
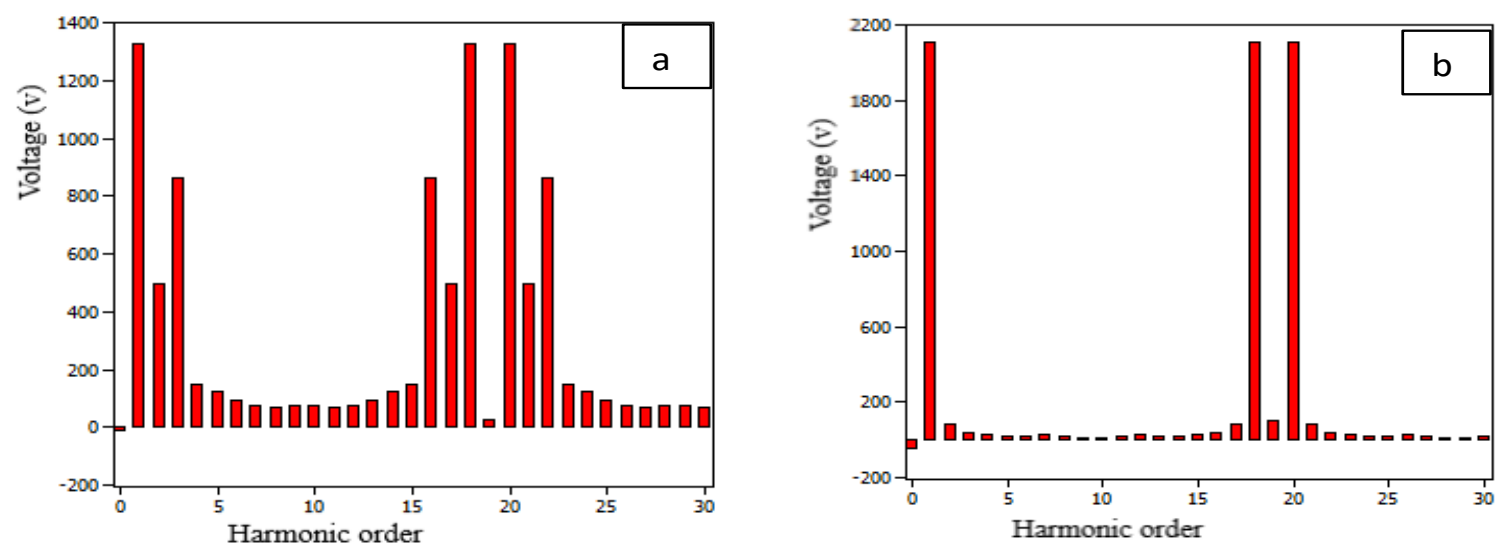

Figure 9. (a) FFT analysis of ferroresonant waveform during opening on ATP and (b) FFT analysis of ferroresonant waveform during closing on ATP

\section{Modelling DFIG Wind Turbine on Simulink/Matlab}

The model of DFIG wind turbine configuration implemented on simulink is shown in Figure 10. Most of the components exist as preset blocks in the simulink library. It entails modelling of DFIG wind turbine and generator, converters and their control and three phase, three winding transformers.

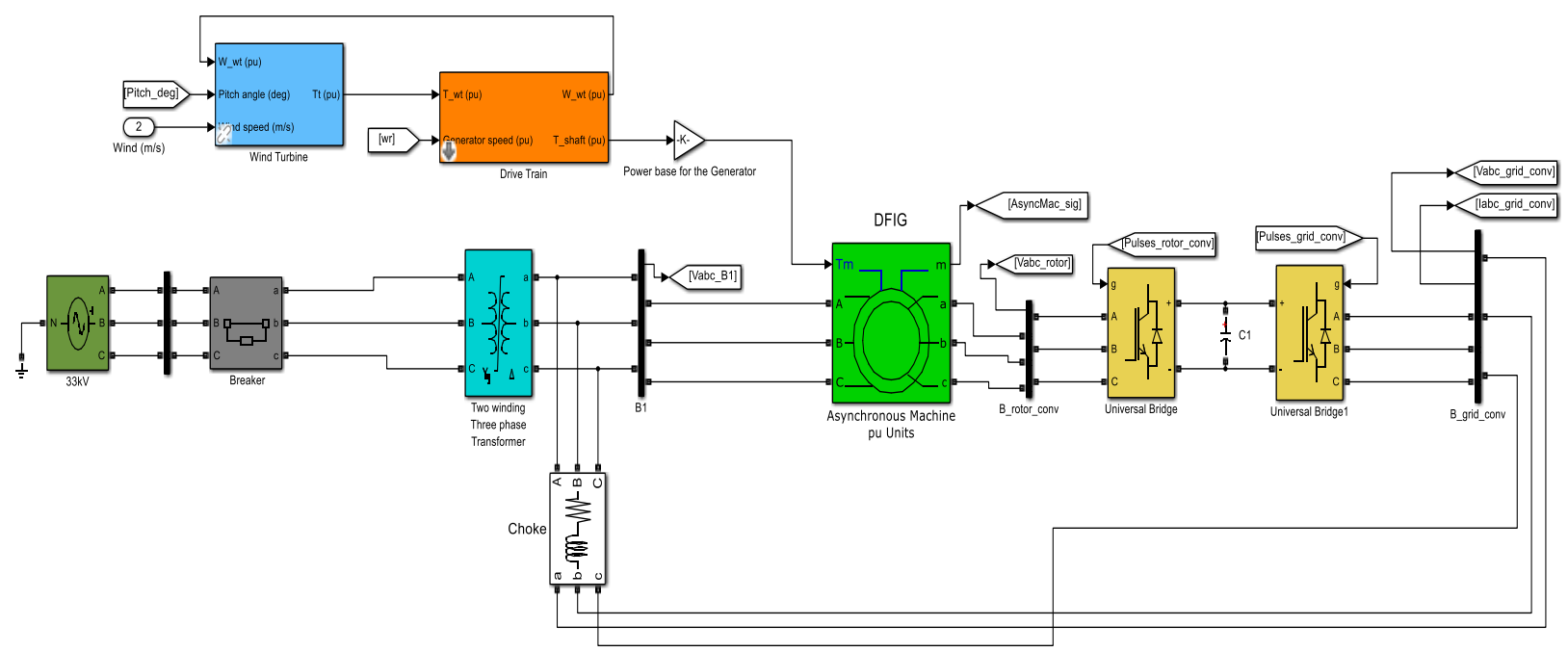

Wind Turbine Control

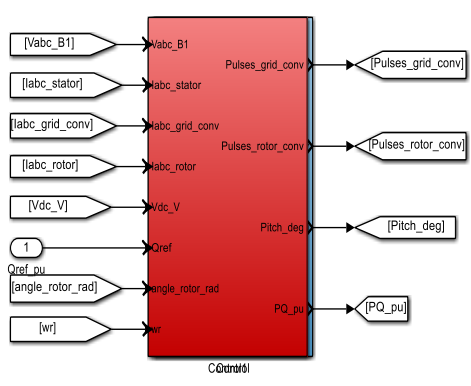

Figure 10. Overview of DFIG wind turbine configuration on Simulink/MATLAB 


\subsection{DFIG Wind Turbine and Generator Modelling on Simulink}

This was implemented as a block using Equation 1. The wind speed was input by implementing Equation 1 and maximum $C_{p}$ is determined by Equation 2 modelled by a look-up wind turbine characteristic curve $C_{p}(\lambda, \beta)$. The output torque was input to the shaft of the generator. The mechanical elements of the turbine were also added such that the stiffness of the drive train is infinite, the friction and inertia of the turbine were modelled using single-mass model.

Generator was modelled by using asynchronous machine block already present in the simulink library. This could act as either motor or generator depending on polarity of mechanical torque, $T_{m} . T_{m}$ was input in to this block, while resistance and inductance for both rotor and stator were also input as parameters presented in Table 1.

\subsection{Matlab Modelling of Back-to-Back Converter and Control}

Both converters were modelled using universal bridge block and IGBT already exists as a block in Simulink. Implementation of converter control as shown in Figure 10 was implemented using Math operation blocks.

\subsection{Modelling Wind Turbine Transformer on Simulink}

Wind turbine transformer was modelled using preset three phase, two winding transformer blocks. The parameters for the core, primary and secondary winding is shown in Table 5. A nonlinear characteristic curve presented in Figure 6 was used for core saturation.

Table 5. Parameter of wind turbine transformer

\begin{tabular}{lll}
\hline Parameters & Primary & Secondary \\
\hline Vector group & D & Y \\
R $(\Omega)$ & 0.002 & 0.42 \\
L $(\Omega)$ & 0.0327 & 13.41 \\
\hline
\end{tabular}

Time step and sample time of $5 \mu$ s and 3 s respectively were chosen for the simulation. The voltage during normal operation of DFIG wind turbine on Simulink is shown in Figure 11.

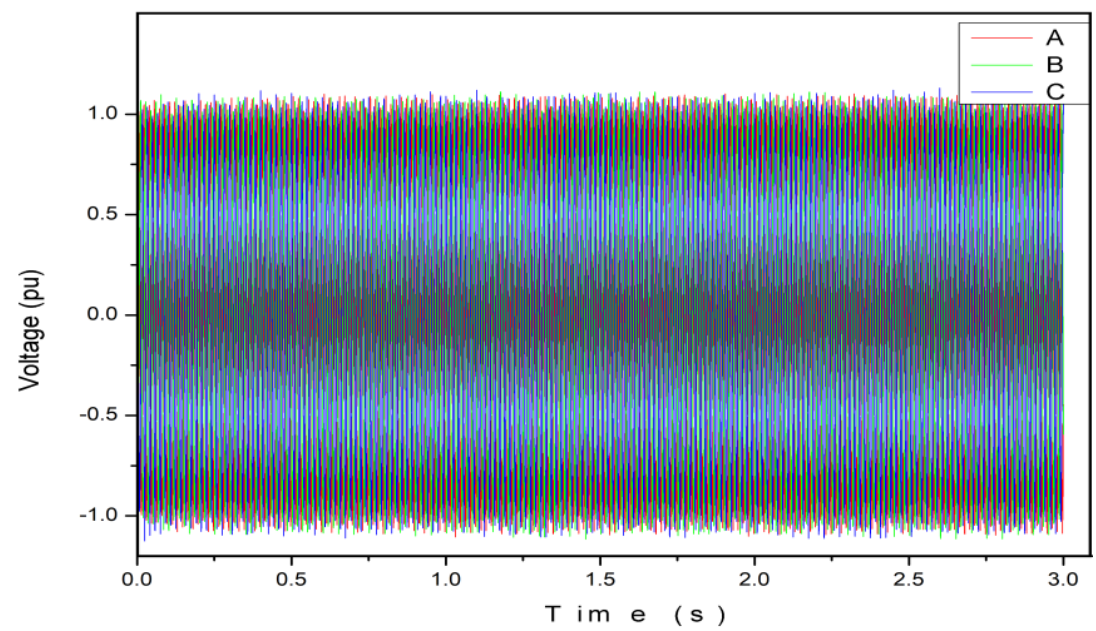

Figure 11. Output voltage during normal operation on Simulink

\section{RESULTS ON SIMULINK}

\subsection{Simulation of Ferroresonance on Simulink/Matlab}

Figure 12a and 12b show the ferroresonant overvoltage during opening and closing of circuit breaker in an event of one stuck pole, with overvoltage of 4.63 P.U. and 6.36 P.U. accordingly. 

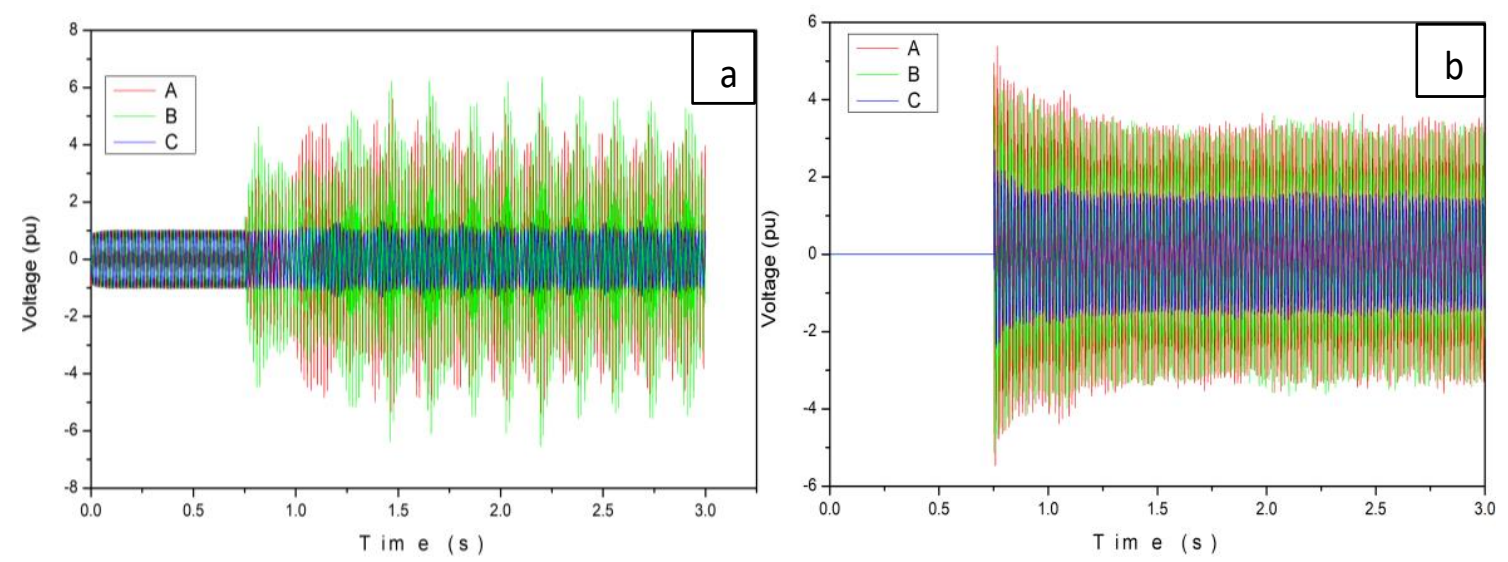

Figure 12. (a) Output voltage due to a stuck pole during circuit breaker opening on Simulink and (b) Output voltage due to a stuck pole during circuit breaker closing on Simulink

\subsection{Characterization of Resultant Ferroresonance on Matlab}

Simulink/Matlab can carry out further analysis on the ferroresonance, for the purpose of understanding the characteristic of the ferroresonance and to determine the risk level it poses to power equipment. Figure 13a and 13b show the FFT analysis performed between $0.8 \mathrm{~s}$ to $1.5 \mathrm{~s}$ of waveform for the opening and closing ferroresonant events respectively. The spectrum of frequency during the opening and closing events show that the magnitude are high on $1^{\text {st }}, 3^{\text {rd }}, 5^{\text {th }}$ and $7^{\text {th }}$ order of harmonics.
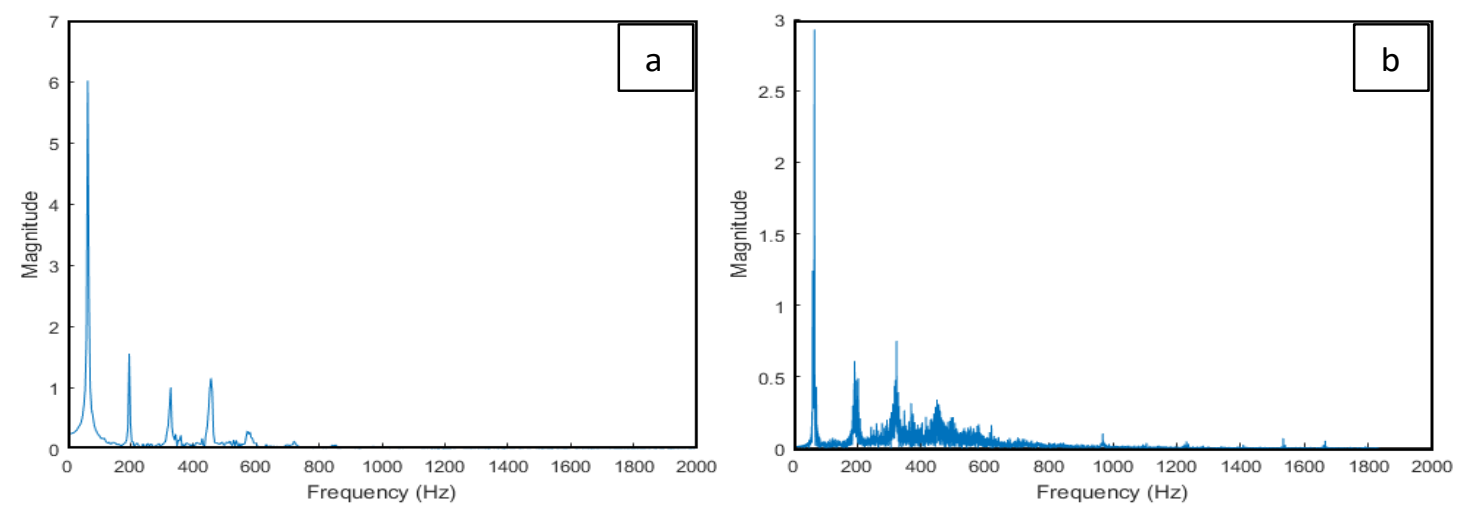

Figure 13. (a) FFT analysis of ferroresonant waveform during opening on Simulink and (b) FFT analysis of ferroresonant waveform during closing on Simulink

However, it is quite difficult to characterize ferroresonance by just observing the waveform or by performing FFT analysis. Further analyses that could be done are phase plane and Poincaré mapping. Phase plane shows the periodicity of signal produced by a non-linear system, since the periodic signal follows a closed-loop trajectory [16]. Observation of the trajectory of the phase plane diagram indicates the classification of the ferroresonance existing in the system where a single closed path represents existence of fundamental ferroresonance mode, while existence of 2 or 3 closed paths represent subharmonic ferroresonance mode. Multiple closed paths depict quasi-periodic mode and irregular multiple paths show chaotic mode exists in the system.

Poincaré map is named after Henri Poincaré a French scientist that founded it. It is the point of intersection of a periodic orbit in signal of a non-linear dynamic theory where a single point of intersection depicts fundamental ferroresonance mode while existence of 2 or 3 points represents subharmonic ferroresonance mode. Multiple number of points with closed path and multiple points with irregular path depict quasi-periodic mode and chaotic mode respectively. Poincaré mapping is done by sampling the peaks of voltage and output signal at power frequency [17]. Both phase plane and Poincaré mapping were done to further characterize the ferroresonance to differentiate between the two modes. Figure 14a and 14b show the phase plane diagram for the opening and closing events respectively, while Figure 15a and 15b show the Poincaré 
mapping for opening and closing events accordingly. The ferroresonance mode was chaotic mode for opening event because the phase plane diagram had chaotic periodic circular path, which connotes extreme disturbance and quasi-periodic mode for closing event because of its closed multiple loops. While the Poincaré map depict chaotic mode for opening event since the points are scattered and quasi- periodic for closing event which shows multiple number of point clustered together.
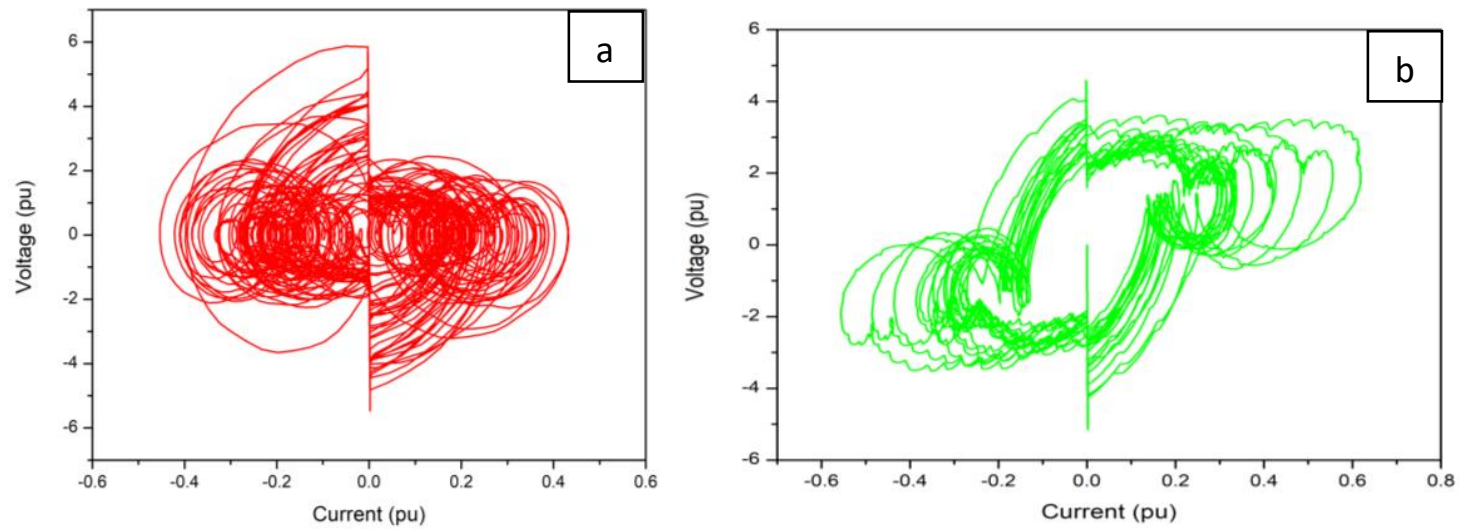

Figure 14. (a) Phase plane diagram of ferroresonant overvoltage during opening operation on Simulink and

(b) Phase plane diagram of ferroresonant overvoltage during closing operation on Simulink
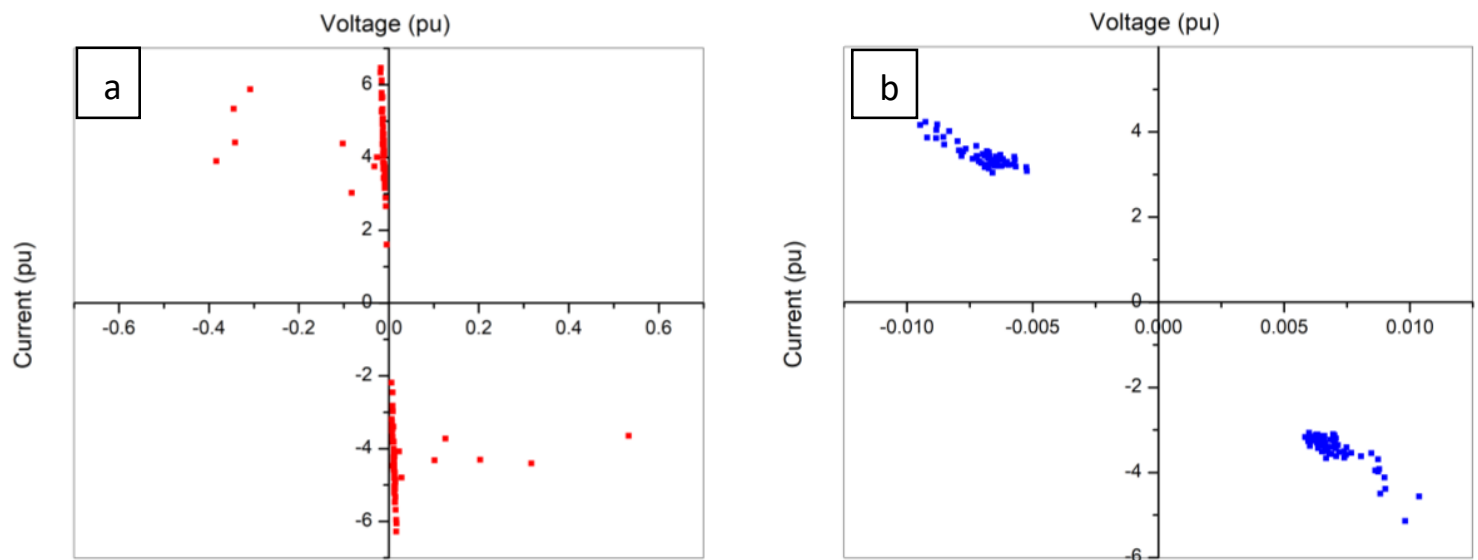

Figure 15. (a) Poincaré mapping of ferroresonant overvoltage during opening operation on Simulink and (b) Poincaré mapping of ferroresonant overvoltage during closing operation on Simulink

\section{CONCLUSION}

There were discrepancies between the two software packages for the two simulated ferroresonance events; overvoltage results obtained on ATP were higher than that of Simulink. The time of simulation for ATP was 110.58 secs and that of Simulink was 130.81 secs which showed that ATP faster than Simulink. Overvoltage of 4.22 P.U. and 3.77 P.U. was experienced during opening and closing event respectively on ATP/EMTP model while overvoltage of 6.36 P.U. and 4.63 P.U. was experienced during opening and closing event respectively on Simulink model. The difference in results observed between the two packages could be from the preset model of the components in the two software and not from the solver algorithm of the software this is in agreement with finding of [6]. Any change in parameters when analyzing ferroresonant condition can cause change in the behaviour of the system because of extreme sentivity of ferroresonance phenomenon. Meanwhile, Simulink was found to be more user-friendly and easier to use for wind turbine simulation due to availability of electrical power components as blocks in its library.

Characterization of the ferroresonance using ATP/EMTP could not easily be determined as FFT analysis could only be performed on it. Phase plane diagram and Poincaré mapping performed on Matlab showed that chaotic mode and quasi-periodic mode ferroresonance occurred in opening and closing switching events rspectively. Thus, Simulink/Matlab allows post-processing of signals for better understanding and 
characterization of such signals while ATP is limited in this aspect. However, signal output from ATP can be imported to Matlab for further analysis.

\section{REFERENCES}

[1] Muller S, Deicke M, De Doncker RW. Doubly fed induction generator systems for wind turbines. IEEE Industry applications magazine. 2002;8(3):26-33.

[2] Ferracci P. Additional Reference Schneider Electric CT 190 Ferroresonance. In: Electric S, editor. Cahiers Techniques 1998.

[3] Rezaeealam B, Norouzi B. Investigating Ferroresonance Phenomenon in a Single-Phase Transformer with the Effect of Magnetic Hysteresis. Indonesian Journal of Electrical Engineering and Computer Science. 2016;2(2):248-58.

[4] Alves R, Orizondo R. UPFC Simulation and Control Using the ATP/EMTP and MATLAB/Simulink Programs. IEEE PES Transmission and Distribution Conference and Exposition Latin America, Venezuela; 2006.

[5] Danyek M, Handl P, Raisz D. Comparison of simulation tools atp-emtp and matlab-simulink for time domain power system transient studies. European EMTP-ATP User Group Meeting; 2002.

[6] Khan A, Bengiamin N. Matlab/Simulink Simulation Of Arc Faults. International Journal of Engineering Research and Innovation. 2016;8(2).

[7] Schavemaker P, De Lange A, Van der Sluis L. A comparison between three tools for electrical transient computations. International Conference on Power Systems Transients, IPST, Budapest, Hungary. 1999.

[8] Barsali S, Ceraolo M. simulation of electromagnetic transients in power systems: a comparison between ATP/ATPDRAW and SIMULINK/PSB environments. International Conference on Power Systems Transients, IPST, Rio de Janeiro, Brasil; 2001.

[9] Prikler L, Høidalen HK. ATPdraw Version 5.6 for Windows 9x/NT/2000/XP/Vista-Users' Manual. European EMTP ATP Users User Group. 2009.

[10] Kadali KS, Rajaji L. Evaluation of Energy in Wind Turbine System Using Probability Distribution. Indonesian Journal of Electrical Engineering and Computer Science. 2018;9(2):294-8.

[11] Akinrinde AO, Swanson A, Tiako R. Investigation of Temporary Overvoltage on Microgrid with Emphasis on Ferroresonance. International Journal of Engineering Research in Africa. 2018;39:32-46.

[12] Cigre. Guidelines for Representation of Network Elements when Calculating Transients. CIGRE Brochure 391990.

[13] ATP. Electronic Edition of the ATP Rulebook in PDF Format. 2001.

[14] Aristi IA. Modeling of switching transients in Nysted Offshore Wind Farm and its comparison with measurements:EMT simulations with Power Factory and PSCAD: Technical University of Denmark, DTU, DK-2800 Kgs. Lyngby, Denmark; 2008.

[15] IEC. 60071-1. Insulation Co-ordination-Part 2006. p. 67.

[16] Escudero MV, Dudurych I, Redfern M. Characterization of ferroresonant modes in HV substation with CB grading capacitors. Electric Power Systems Research. 2007;77(11):1506-13.

[17] Corea-Araujo J, Gonzalez-Molina F, Martinez-Velasco J, Barrado-Rodrigo J, Guasch-Pesquer L. Tools for ferroresonance characterization. European EMTP-ATP User Group Conference; 2012. 